\title{
Study on the Establishment of A New Teaching System of Higher-education Military Curriculum under the Emerging Situation of Intensified Reform and Innovation
}

\author{
Shanhua Luo \\ Military Teaching and Research Section \\ Harbin Institute of Technology \\ Harbin, China
}

\author{
Gongchen $\mathrm{Su}$ \\ Military Teaching and Research Section \\ Harbin Institute of Technology \\ Harbin, China
}

\begin{abstract}
The establishment of the teaching system on every specialty curriculum in colleges and universities responds directly to the teaching purpose and training goal, it's not only a requirement for the personnel cultivation in higher education which shall have the appropriate structure of knowledge and level of ability and quality but also one of the important contents of the basic teaching construction. Due to the increasingly demanding standards for personnel training in modern society, it's a major task to strengthen the construction and reform of higher-education military curriculum teaching and to establish an up-to-date related teaching system under the emerging situation. The basic idea is to build a new teaching system with proactive, strategic and realistic characteristics.
\end{abstract}

Keywords-higher-education military curriculum; teaching system; reform and innovation; characteristics

\section{INTRODUCTION}

Higher-education military curriculum is important part and embodiment of China's national defense education. The nature of it is as described in the Teaching Outline for Military Curriculum in General Institutes of Higher Education issued by the Ministry of Education: "Military curriculum is compulsory for undergraduates and associatedegree students in colleges and universities, which accord with that education should be oriented to the needs of the modernization, the globalization and the future, meet the demand of China's strategic objectives of personnel cultivation and reinforced reserve forces building for national defense, and be of service to the training of highquality socialist cause builders and defenders" [1]. Due to the increasingly demanding standards for personnel training in modern society, the status and role of military teaching is particularly important in higher education. Therefore, it's imperative for us to strengthen the reform and innovation of military teaching for further normalization and for the establishment of a new teaching system of higher-education military curriculum compatible with the requirements of the times.

\section{ESTABLISH A NEW TEACHING SYSTEM OF HIGHER- EDUCATION MILITARY CURRICULUM WITH PROACTIVE CHARACTERISTIC}

The new revolution in military affairs shows an accelerating trend along with the changes of epoch and the rapid development of scientific technology. This information-centered revolution is about to develop into a profound military revolution that will affect the whole world and involve all military fields. As the principal channel of national defense education, the military teaching has to get proper nourishment from the new revolution in military affairs to retain its vitality. That is to say, the establishment of the teaching system of higher-education military curriculum must accurately reflect the cutting-edge and the most revolutionary changes in military field, which means it shall focus on the military changes and the development of international strategic environment, be proactive and with new era charisma.

\section{A. The Military Curriculum Setting Shall Have New Era Connotation}

The young students in colleges and universities nowadays are open-minded, active, with an acute insight and knowledge-seeking mind towards new concepts, new things and new theories. Hence, by keeping in step with the new requirements of era developments and sticking to the mindset characteristics of young students, the military teaching shall accurately grasp the epochal characteristics of current military revolution and constantly integrate the basic issues into military teaching, such as the historical background and developing trend of new military revolution, the current situation of the revolution in military affair all over the world and the special law of Chinese characteristics military revolution. Elaborate new theories with new knowledge and spur new ideas with new information. Without the key theoretical issues about the new revolution in military affairs, the higher-education military teaching would lose the required era charisma and cannot properly reflect the complete system of higher-education military 
curriculum. As world's conditions in military, political, economic, diplomatic and cultural fields change from time to time, some of the traditional curriculum contents become obsolete, and the contents in military curriculum must be constantly updated, namely, new information in every teaching.

\section{B. The Military Curriculum Setting Shall Be Infused with New Hot Issues}

The higher-education military teaching must keep up with changes of world situation and seek to timely bring in students' most-concerned topics about the developments in international strategic environment as well as world's hot issues, latest information and related cutting-edge problems, arousing young students' interest for military theory learning with new hot topics and furnishing life and vigor to the military curriculum setting [2]. Besides, young students focus on broadening their views of military knowledge and value the information in knowledge and the introduction of technology-laden contents. These are what young students are interested in and can be used as the breakthrough point to inspire students' passion for military curriculum learning. Teaching theories in terms of theory must be avoided. Based on exposition of basic theory, try to take some hot issues and students-interested cases as arguments, teach theory through case and interest, and combine theory and knowledge with fun, thereby making the higher-education military curriculum considerably appealing.

\section{Establish A NeW TEACHING S ystem OF Higher- EDUCATION MILITARY CURRICULUM WITH STRATEGIC CHARACTERISTIC}

Colleges and universities are the major base for personnel cultivation and teaching is the central task of higher education. As important part of Chinese higher education, the military curriculum, in terms of its very nature, must meet the demand of China's strategic objectives of personnel cultivation and reinforced reserve forces building for national defense, and be of service to the training of highquality socialist cause builders and defenders. Therefore, the fundamental way for the improvement of military teaching quality and cultivation of high-quality socialist cause builders and defenders is to do a good job in curriculum construction practice and theory innovation, the primary mission of which is to establish a new teaching system of higher-education military curriculum. In this sense, the curriculum teaching system shall have a strategic characteristic.

\section{A. The Military Curriculum Setting Shall Be Centered on and Directed with the Training Goals}

From the theory of curriculum teaching, establishing favorable training goals and personnel development modes as well as giving close attention to ability training is required by our times. Young students in colleges and universities with poor abilities and qualities cannot meet the needs of national construction and national defense construction. Thus, emphasis shall be laid on ability training and quality-oriented education improving in curriculum setting. Namely the curriculum teaching system contains the contents not only about ability training but also about quality-oriented education. As the growth of human abilities is inseparable from the improvement of human qualities, combining them in an organic way is the essential target of curriculum construction. In teaching practices, we shall have a good grasp of the depth of military theory teaching and military skill training, that is, theory teaching needs to focus on the vertical depth and horizontal scope of curriculum while skill training should highlight the cultivation of students' practical application of military knowledge. Only in this way can a scientific and reasonable curriculum teaching system be established for students' ability training and quality improving.

\section{B. The Military Curriculum Setting Shall Be Aimed at Developing Students' Ability of Strategic Thinking with the Focus on Scientific and Advanced Military Theory Education and Application}

In higher-education military teaching, having a good command of the essence of ancient and contemporary military theories is a must for young students. Moreover, they shall be trained to correctly understand domestic and international military strategies and strategic decisions, analyze world's military strategic situation and the changes of international strategic environment, and increase the awareness and ability of consciously serving for national construction and national defense construction. Namely young students should have the ability of military strategic thinking and be able to strategically understand and analyze problems. While this ability cannot be naturally obtained, it must be achieved through military teaching. Only by systematically teaching students the world's as well as ancient Chinese fine military culture and scientific military theories can we help them arm the mind with correct and scientific military theories, thereby continuously improving their ability of military strategic thinking ad ensuring their military strategic thinking with right stand, method and direction. Higher-education military curriculum needs to "propagate the doctrine", to "impart professional knowledge" and even more to "solve doubts". The highest stage of "solving doubts" is to enable students to conduct military strategic thinking and enhance the ability to understand, analyze and solve problems at a macro level. Strategic thinking is an advanced military macro-thinking, belonging to the highest level of military thinking. For this reason, it shall be taken as the fundamental goal in the planning and launching of higher-education military curriculum setup.

\section{ESTABlish a NeW TEACHING SYSTEM OF HigheR- EDUCATION MILITARY CURRICULUM WITH REALISTIC CHARACTERISTIC}

At present, the higher-education military teaching is moving from a primary stage toward a higher level. Meanwhile, just like the construction of other curriculums, the construction of higher-education military curriculum is a complicated systematic project. In macroscopic view, the key question is to straighten out the relations, optimize the 
structure, establish and perfect the scientific and reasonable curriculum teaching system. Seen from the military teaching system, it's critical to correctly handle the relation between skill training and theory teaching. From the perspective of the overall structure of military curriculum, it's crucial to achieve comprehensiveness, serialization and expansibility and broaden the scope of knowledge. The military curriculum shall be set based on the needs of teaching practices during the establishment of a new teaching system. Judging from this aspect, the curriculum teaching system shall have a realistic characteristic.

\section{A. Lay Emphasis on the Comprehensiveness of Military Curriculum Setting}

The reform of curriculum contents determines the success of curriculum construction and is the focus of it. From the perspective of system engineering, the contents of military curriculum shall be re-combed and re-integrated and a comprehensive curriculum appropriate to the main and characteristic courses in military discipline shall be constructed. It's important to achieve innovations in the main basic theory courses on military thoughts, modern national defense, international strategic environment, military hightech and IT-based warfare, etc. and to solve major issues about national defense construction and military conflicts with the latest military theories. In the practical application of military theories, breakthroughs shall be made to arouse the enthusiasm of young students in the analysis and study of realistic problems, such as the challenges that the world and China are facing. With increase in the proportion of the teaching contents of military thoughts and strategies, characteristic courses shall be offered, including Modern Military Thoughts of the World, Ancient Chinese Military Thoughts, Proletarian Military Thoughts, Military Thoughts of Mao Zedong, Contemporary Military Strategies of the World, etc. In addition, consistent prominence shall be given to Marxist-Leninist military theories as well as China's great military thoughts of Mao Zedong in military teaching. In order to enable young students to grasp these military theories and basic principles in a comprehensive, systematic and profound way, breakthroughs shall be achieved in strengthening the guidance of military theories to help them develop the overall consciousness and improve the ability consciousness.

\section{B. Lay Emphasis on the Serialization of Military Curriculum Setting}

Higher-education military curriculum involves a plenty of fields of military discipline, with interrelated contents constituting a complete teaching system. In accordance with the requirements of the Outline issued by the Ministry of Education, the contents of higher-education military curriculum are mainly composed of two major parts which respectively are military skill training and military theory teaching. Military skill training contains: education and training of rules and regulations, light weapons firing, tactics, military topography, combined training and so on. While military theory teaching includes military thoughts, modern national defense, international strategic environment, military high-tech and IT-based warfare, etc. The arrangement of this series of courses is firmly concentrated on the realization of educational and teaching objectives, covering the basic knowledge of military theories and the basic military skills that young students should master [3], which indicates not only the introduction of rich theoretical knowledge but also the requirement of great practical ability. In this sense, sufficient attention shall be paid to the coordination of the relationship between skill and theoretical classes, with ability development as the key to form a series of courses that meet the needs of ability training. For instance, the courses of military thoughts and military hightech have highly theoretical and academic value; and training courses such as queuing, tactics and shooting shows prominent practical operability. There are also courses which are comprehensive training of knowledge and ability in themselves, such as military topography, orienteering, field survival training and so on. Taking the course of military topography for example, it requires students not only to possess the knowledge of map reading but also to master the practical capacity of map using. In a similar fashion, series of alike courses shall be constructed in curriculum setting to improve the comprehensive quality of young students and to develop their practical application ability.

\section{Lay Emphasis on the Supplementary Feature of Military Curriculum Setting}

The contents of higher-education military curriculum currently cover almost all aspects of the military science which in itself is quite theoretical and systematic. The coverage of a wide and intensive range in content makes it difficult for young students to fully digest and understand the teaching contents in the limited class. Therefore, supplementary or introductory courses shall be offered according to the needs of students with different majors and different levels. Some particular measures to be taken are as the followings: to set up optional courses, hold a series of lectures on military theories and provide online answering questions and consulting, etc.; to timely introduce students the latest achievements as well as future directions regarding various military theories, military academics, military hi-tech and other relevant aspects; to teach them the most advanced concepts of national defense, the development trends of armed forces all over the world and the possible aspects of future war. In summary, efforts shall be made in enriching and expanding military contents as well as in enhancing the radiating capacity and appeal of military courses, thereby constructing multi-level, multi-direction and multi-type supplementary courses.

\section{Lay Emphasis on the Highly Technical Nature of Military Curriculum Setting}

There are an enormous variety of specialties offered in China's colleges and universities, especially in those of science and technology, and the specialty setting has highly professional and technical nature. It's essential to proceed from the training objective of each specialty, improve the high-tech level and increase the proportion of the contents about new knowledge, new technologies and managerial approaches, and combine the military teaching content setting with the entire teaching content system of each 
specialty. The teaching content systems can vary considerably due to the different levels of and majors in colleges and universities, which leads to the campus culture atmosphere with distinctive features. The military teaching content setting shall be merged with these teaching content systems of different higher-education specialties. For instance, necessary contents about nuclear defense, biochemical attack and so on can be taught to biological and chemical majors; and for medical students, trainings like battlefield rescue can be offered [4]. In general, to establish a new teaching system of military curriculum of its own, we shall manage to seek for a merging point in teaching system setting.

\section{CONCLUSION}

The establishment of the teaching system on every specialty curriculum in colleges and universities responds directly to the teaching purpose and training goal, it's not only a requirement for the personnel cultivation in higher education which shall have the appropriate structure of knowledge and level of ability and quality but also one of the important contents of the basic teaching construction. To make sure the higher-education teaching reform successful, we must meet the increasingly demanding standards for personnel training in modern society and start with the construction of curriculum teaching system which is also the emphasis and difficulty of overall teaching reform. In this sense, the establishment of a new teaching system of highereducation military curriculum is an important guarantee for the effective implementation of teaching programs as well as for the improvement of teaching level and personnel training quality.

\section{REFERENCES}

[1] Ministry of Education, General Staff \& General Political Department, Teaching Outline for Military Curriculum in General Institutes of Higher Education (revised in 2006) [Z]. JTY [2007] No. 1 Document:

[2] Liao Wenke, Proceedings of China's 5th Academic Conference on National Defense Education in General Institutes of Higher Education [M]. Beijing: Higher Education Press, 2011:106.

[3] Students' Military Training Office of Shenyang Military Area Command, Assembly of Solicited Articles of Theoretical Discussion on Students' Military Training [G]. Shenyang: Issued by Students' Military Training Office of Shenyang Military Area Command, 2010:300.

[4] Fu Wendi, To Improve Quality Innovations and Practices of Higher Education [M]. Harbin: Heilongiiang Educational Press, 2010:715. 